\title{
“LA DiSPOSICIÓN DE ÁNiMo (O DE ESPÍRITU)" EN MAX SCHELER: ELEMENTOS PARA LA ORIENTACIÓN FILOSÓFICA
}

\author{
RenÉ PÉREZ MonTIEL \\ Universidad Vasco de Quiroga, México \\ filosofiauvaq2007@hotmail.com
}

RECIBIDO: 15 DE FEBRERO DE 2009

ACEPTADO: 12 DE ABRIL DE 2010

“¡Llega a ser quien eres!” (Píndaro)

"Asume todos los riegos, porque cada momento de amor equivale a la eternidad entera; y una vida sin amor (comprensivo) podrá ser inmortal, pero será sólo un cementerio..." (Osho)

Resumen. Los escritos de Max Scheler tocan el problema de las causas, efectos, significación filosófica y religiosa del drama central de la vida. Scheler desarrolló una antropología o axiología de la persona que intenta resignificar intelectual y moralmente, a través de la fenomenología, el valor esencial del hombre. Asume que sólo un detenido examen vivencial (unido a una disposición de ánimo especifica) de la persona humana permite una apreciación justa del hombre en el cosmos con una esencia suprema de valor único y trascendente. Este artículo vincula esas concepciones con la Filosofía Aplicada.

Palabras clave. Persona, espíritu, esencia, conocimiento apriórico, orientación filosófica.

Abstract. Max Scheler's writtings relate to causes, effects, philosophical and religious meanings of central issue of life. Scheler developed an anthropology and axiology of the person that aims to recreated the essential value of human beings through a phenomenological approach. He defends that it is necessary a vital test of persons and a soul disposition to get a good knowing human beings as supreme value. This article links this conceptions to Philosophical Practice.

Keywords. Person, spirit, essence, apriorical knowledge, philosophical counseling

\section{Scheler y su relación con la Filosofía Aplicada}

Hans-Georg Gadamer escribe: 
Es poco menos que increíble, pero si un joven interesado en la filosofía, e incluso un hombre mayor, tuviera hoy que decir quién fue Max Scheler, difícilmente obtendría respuesta. Es posible que ambos tuvieran una idea más o menos vaga de que están hablando de un pensador católico que escribió una influyente Ética material de los valores, y perteneció de algún modo al movimiento fenomenológico fundado por Husserl y luego continuado por Heidegger. La suya, sin embargo, no es una presencia comparable a la que Husserl o Heidegger poseen en la conciencia filosófica del presente. ¿Por qué razón es así? ¿Quién fue Scheler? ${ }^{1}$

El filósofo alemán que habiendo nacido en Munich el 22 de agosto de 1874 y muerto en Frankfurt el 19 de mayo de 1928, es considerado uno de los pensadores más influyentes del siglo XX. Reflexionó sobre materias filosóficas fundamentales: religión, política, sociología, psicología y antropología, aunque su auténtico eje medular de todas ellas ha de buscarse en sus preocupaciones éticas. Prueba de esto, es que bajo la dirección de Eucken, principal guía de su formación, elaboró, en 18971899, las dos tesis que le habilitaron para la enseñanza superior. La primera versa sobre las relaciones entre los principios lógicos y éticos, y la segunda bajo el título el método trascendental y el método psicológico (Leipzig 1900).

En el año de 1901 tiene su primer contacto y conocimiento personal con Husserl en la que es atraído por la novedad de sus doctrinas. Motivo que lo llevó a introducirse en el grupo de jóvenes fenomenólogos de Munich en el año de 1907, ${ }^{2}$ adhiriéndose, sobre todo, a las nuevas ideas no sin discusión y crítica, buscando nuevas líneas de desarrollo de las mismas. Lugar donde desarrolló el contenido de sus primeras obras de madurez: El formalismo, la que ha sido el producto de una serie de cursos consagrados a la ética.

Así, Scheler comienza en su vida intelectual a ser extraordinario y fecundo con ininterrumpidas publicaciones: El resentimiento en la elaboración de las morales, 1912; El formalismo en la ética y la ética material de los valores, que apareció por primera vez en Jahrbuch de Husserl entre 1913 y 1916. Aunque, ya para esta época, reside en

\footnotetext{
${ }^{1}$ GADAMER Hans-Georg, Mis años de aprendizaje, Herder, Barcelona, 1976. p. 77

${ }^{2}$ Entre los que cabe mencionar a Adolfo Reinach, Alejandro Pfänder, Mauricio Geiger, Oscar Becker. Cfr. URDANOZ, Teofilo, Historia de la filosofía VI, Siglo XX: De Bergson al final del existencialismo, Madrid, BAC, 1988. pp. 405-406
} 
Gotinga, ${ }^{3}$ tuvo frecuente contacto con Husserl. Sin embargo, la crítica (de Scheler) contra él se hizo más declarada por el giro trascendentalista que tomaba su filosofía, y al parecer las ideas de éste, en que los objetos se reducen a meras estructuras de la conciencia pura, su actitud se convierte en franca oposición a él. ${ }^{4} \mathrm{Y}$ es así que los temas de sus escritos son nuevos y que además, al estallar la primera guerra mundial, el problema de las causas, efectos, significación filosófica y religiosa de la misma pasan a primer plano, en donde sus publicaciones y conferencias posteriores se ligan a este drama central e intensamente vivido. Razón fundamental, quizás, sin saberlo él, que hace de su filosofía, una filosofía aplicada. Desarrolla toda una antropología personalista o una axiología de la persona donde intenta resignificar intelectual y moralmente, a través de la fenomenología, el valor esencial del hombre. El propio Scheler escribía introduciendo El puesto del hombre en el cosmos: "Las cuestiones: ¿qué es el hombre, y cuál es su puesto en el ser? me han ocupado más profundamente que cualquier otra cuestión filosófica desde el primer despertar de mi conciencia filosófica" ${ }^{\text {"5 }}$. En consecuencia, asume que sólo un detenido examen vivencial de la persona humana permite una apreciación justa del hombre en el cosmos con una esencia suprema de valor único y trascendente.

Entre sus ensayos destacan: El genio de la guerra y la guerra alemana (1915), Guerra y reconstrucción (1916), Las causas de odio a Alemania (1916), Misión de Alemania y el pensamiento católico (1918). En el fondo su pensamiento buscó la unidad espiritual de Europa, basada en un nuevo sentido de solidaridad que sólo puede realizarse por una plena conversión moral dentro de los principios cristianos. Además, de haber resuelto la evolución espiritual de Scheler hacia la Iglesia católica, sus demás escritos reflejan sus convicciones cristianas: De la inversión de los valores, 1919; Lo eterno en el hombre, 1921; Esencias y formas de la simpatía, 1923. Sin embargo, el pensamiento de Scheler influido por los presupuestos de la teología liberal, protestante y modernista, da un giro y esboza una crítica global de la dogmática cristiana que ya le resulta incompatible. Así, es representativa su obra: Las formas del saber y de la

\footnotetext{
${ }^{3}$ Lugar en el que se dieron encuentros con otros discípulos de Husserl: Edith Stein, Eduvigis ConradMartius, Dietrich von Hildebrand. Ibid. pp. 407-410.

${ }^{4}$ Ibid., pp. 411-412

${ }^{5}$ SCHELER, Max, El puesto del hombre en el cosmos, Buenos Aires, Losada, 1967, p.29.
} 
sociedad, 1926; y, junto a ésta, El puesto del hombre en el cosmos, 1928: en la que deriva en un panteísmo evolucionista por influencias del romanticismo germánico. ${ }^{6}$

Toda esta producción convierte a Scheler en un gran hombre del pensamiento filosófico del siglo XX. Sin embargo, no es sistemático como los grandes pensadores clásicos de la historia de la filosofía (Aristóteles, Kant, Hegel), pues, su pensamiento tiene una connotación diferente. La primera preocupación es de orden ético, si se da al término el sentido amplio reconquistado por gran parte del pensamiento actual. A este respecto su antirracionalismo es una constante de su pensamiento. ${ }^{7}$ Como se percibe en sus obras, dirá que, entre el pensar, el querer, el saber y el obrar, lo bueno y lo verdadero hay un insalvable abismo. Dicho de otro modo, los actos éticos no son reducidos a actos puramente lógicos, sino que responden más bien a la esencia y por tanto al valor por sí mismo que es objeto de la intuición fenomenológica. Esta tesis es el tema básico de su obra El formalismo en la ética y la ética material de los valores. Toda su fundamentación de la ética en la axiología remite, en última instancia, a una nueva visión del hombre alejada del racionalismo en un intento de recuperar el tema pascaliano de la lógica del corazón, ${ }^{8}$ expresamente contrapuesta a la visión del hombre que late en las éticas vigentes: el deber, antes que el ser; la razón, antes que la voluntad, el amor, el sentimiento. En suma esta obra termina con una exposición de la doctrina de la persona. Su problemática filosófica confluye en el problema del hombre y con su olfato de perdiguero, ${ }^{9}$ en expresión de Ortega y Gasset, se percata de que ésta es la cuestión que subyace a las discusiones de su tiempo: "No hay problema filosófico cuya solución reclame nuestro tiempo, con más peculiar apremio, que el problema de una antropología filosófica... Ciencia fundamental de la esencia y de la estructura esencial del hombre". ${ }^{10}$

Con esto se precisa pues, que hay un tema en el cual finalmente inciden todos los pensamientos de Scheler: el hombre, una unidad

\footnotetext{
${ }^{6}$ Dios como vencedor del mal, sólo aparece al final del proceso cósmico y el hombre es el lugar de la deificación. Cfr. URDANOZ, Teofilo, op. cit. p. 414

${ }^{7}$ Hablar de irracionalismo sería equivoco.

${ }^{8}$ Cfr. SCHELER, Max, El puesto del hombre en el cosmos, Buenos Aires, Losada, 1967, p. 11

${ }^{9}$ Cfr. ORTEGA y GASSET, Metafísica de la libertad, Buenos Aires, Losada, 1960. pp. 37-38

${ }^{10}$ SCHELER, Max, La idea del hombre y la historia, Buenos Aires, Ediciones Siglo Veinte, 1967. p. 9
} 
esencial (material y espiritual) en cuanto es un centro realizador de actos de percepción interior y de percepción exterior ${ }^{11}$; es decir, tanto de actos materiales como actos espirituales. Sobre todo, con un enfoque fenomenológico, que circunscribe la realidad del hombre en una importante doctrina filosófica de la esencia, el valor por sí mismo; y, con un enfoque metafísico, que dibuja una doctrina general de la vida espiritual del ser humano, en cuanto que se trasciende a sí mismo, trasciende su vida y toda vida. De tal modo, como afirma Scheler, "el hombre es, visto con rigor, el movimiento, la tendencia, el tránsito a lo divino" 12

\section{Filosofía scheleriana y la orientación filosófica}

Preciso, de este modo, que el nacimiento de la filosofía scheleriana busca responder con especial empeño filosófico al espíritu contemporáneo en el que se encuentra envuelto el hombre, que según Hegel ya desde su tiempo se le percibe como ajeno a su propia identidad con "una conciencia desgarrada". ${ }^{13}$ Para ello, es necesario que vuelva el hombre a encontrarse a sí mismo. Intente palparse en su esencia, en su intimidad, en su espíritu, en su proyecto, en su progreso personal. Tiene que acceder a un conocimiento claro de su estatuto metafísico u ontológico fundado en el reconocimiento de lo que es su valor en sí y por sí. No por las cosas que le rodean, por las que posee o les faltan, por las que hace o lo que deja de hacer sino que ha de medirse desde sí mismo, desde su condición propia, de lo que es y pretende ser. Y es en ello, que el orientador filosófico tiene que pensar cuál será su papel o cómo puede colaborar dentro de la consulta.

Sin embargo, ha de reconocerse, que la metafísica antropológica que asume Scheler es distinta de la metafísica tradicional o filosofía tradicional. No concibe al hombre como una substancia o ser subsistente de naturaleza racional (como lo expresaban Boecio y Tomás de Aquino), sino como "la unidad de ser concreta y esencial de actos de la esencia

\footnotetext{
${ }^{11}$ Cfr. SCHELER, Max, Ética, op. cit., p. 138

${ }^{12}$ Ibid., p. 398

${ }^{13}$ Resalta Francisco Larroyo en su estudio introductivo y análisis de la obra de kant. Cfr. KANT, Manuel, Crítica de la razón pura, México, Porrúa, 2005 (13ª) (Nota preliminar. p. IX)
} 
más diversa o de diversidades esenciales: es decir, tanto racionales, como volitivos, como afectivos" ${ }^{14}$. Entender al hombre sólo como una cosa o substancia simplemente pensada fuera, y tras lo inmediatamente vivido; es caer en una visión parcial de lo que es el ser humano. Si tan sólo se participara del saber conceptual e intuitivo y de los actos específicamente teoréticos pertenecientes a la esfera del saber, no habría más que sujetos lógicos que realizan actos de razón.

"La persona es una unidad inmediatamente convivida del vivir"15 y no puede quedar limitado a ser un sujeto de actos de razón. De lo contrario, es una tentación a la despersonalización. Luego, entonces, el hombre sólo podrá comprender a través de sus actos diversos la esencia de su ser, la evidencia de su ser. Esa pertenencia al mundo de los actos, y no al de los objetos, va a ser lo más característico de la persona. "Un acto no es nunca un objeto", 16 con mayor motivo lo será la persona que vive en su realización de actos. La persona es una actualidad continuada. "Lejos de ser el yo de las vivencias una conexión de vivencias, toda vivencia en sí misma es, por el contrario, plena y adecuadamente dada únicamente cuando es dada en ella justamente el individuo que la vive". ${ }^{17}$ Ciertamente, "no es el yo objeto de cualquier acto, sino del específico acto de la percepción interna, pero resulta realmente objetivado mediante ese acto, que se da colateralmente en toda vivencia". ${ }^{18}$ Sucede de modo análogo a todo objeto de la esfera de la percepción externa, que en la percepción interna se de un yo en general: la totalidad de un yo. De manera que ha de afirmarse como fenómeno irrefutable el dato intuitivo de un yo individual vivencial, que toda vivencia acentúa de un modo peculiar por el carácter y modo individual con que es vivida; y que por ello, está justamente dado en toda vivencia dada de modo adecuado. El auténtico yo, "no es, en consecuencia, una mera suma u ordenación de vivencias"19 sino intuible únicamente en la percepción interna, muy diferente de la observación y de la inducción.

\footnotetext{
${ }^{14}$ SCHELER, Max, Ética, Nuevo ensayo de fundamentación de un personalismo ético, Madrid, Caparrós editores, 2001. p.513.

${ }^{15}$ Ibíd. p. 499.

${ }^{16}$ Cfr. Ibíd. P. 517.

${ }^{17}$ Ibíd. p. 509.

${ }^{18}$ Ibíd. p. 506. Puede observarse este análisis en otra obra: Scheler, Max. Esencias y formas de la simpatía, Sígueme, Salamanca, 2005. Pp. 325, 329.

${ }^{19}$ Cfr. Ibíd. p. 564.
} 
Se desecha, aquí, toda teoría de la persona que basa sus resultados sobre la experiencia inductiva, llámese histórica, psicológica o biológica. Pues, la experiencia sobre el valor por sí mismo o por referencia, presupone el reconocimiento esencial de qué sea valor en sí o no. Cuyo sentido sólo lo reclama la evidencia intuitiva. Pues, la misma reducción fenomenológica, es la que permite de forma inmediata captar la esencia del ser por sí mismo y que no queda por ningún momento atrapado en la individualidad, sino que sólo pertenece a la consciencia de lo dado. $\mathrm{Su}$ presencia se asienta en la conciencia, y sólo desde ahí, se tiene experiencia fenomenológica de la persona humana como una totalidad unificada y esencial, que existe en sí misma con independencia de la naturaleza ciega. La simple presencia que impone lo dado en sí y por sí mismo en la conciencia, lo fundamenta. La conciencia es la realidad que guarda su propia autonomía, y que, aunque puede ser determinada por las individualidades, es la única que por sí misma puede captar al ser, la esencia, el valor independientemente del sujeto y objeto que conoce.

Cabe precisar, con esto, que el método filosófico al que accede Scheler es el propio de la fenomenología (husserliana) donde "para el sujeto no existe otro mundo que aquel que se nos abre desde el fenómeno" "20: la cosa en sí misma o las cosas en sí mismas. En general, esta estricta comprensión fenomenológica del hombre, no se alcanza sino por la propia experiencia de lo dado, producto-reflejo de sus actos y sus conexiones esenciales de la cual es fuente y origen primario. En razón de que, "las conexiones que existen entre las esencias son dadas, intuidas",21 y no producidas o fabricadas por el entendimiento. Es la forma de la intuición íntima en la que el hombre se conduce frente a sí mismo en un intercambio vivo y sentimental con el universo en la intuición de las conexiones esenciales de lo estar dado por sí mismo fundamentando su ser esencial. No por legalidad o derivación de lo a priori, sino por correspondencia con la misma esencia de los actos que revelan su ser y valor.

Por lo tanto, ha de aceptarse el fenómeno como se nos da, pero también sólo dentro de los límites en que se nos da. Se trata, entonces, de hacer epojé (poner entre paréntesis los elementos de la realidad, [un

\footnotetext{
${ }^{20}$ BARRIENTOS RASTROJO, J.: "Husserl y la orientación filosófica", Entre historia y orientación filosófica, Sevilla, X-XI, 2006.

${ }^{21}$ SCHELER, Max, Ética, op. cit. p. 127
} 
método de acercamiento al fenómeno]), de acceder a experiencias de conciencia. Un método para saber qué es esencial y qué no lo es en un fenómeno, ver cómo éste desaparece y aparece. Evaluar la posibilidad de que el fenómeno conserva su esencia primaria.

\section{La disposición de ánimo como elemento para la orientación filosófica}

El hombre es una unidad existencial que se experimenta a sí mismo en su propio acto. Acto en el cual y por el cual puede hacer experiencia fenomenológica de sí. Los actos son el modo práctico de significación unitaria de todo lo que comprende al hombre como una realidad encarnada. En cada acto es dada la materialidad (ver, oír, tocar, nutrirse, crecer,...); la inmaterialidad (pensar, razonar, amar, decidirse, angustiarse,...) y la trascendencia (el proyecto de vida) del ser humano. Es en él en el que se realiza o no, se construye así mismo o no. Para ello, tiene que liberarse de todo libertinaje cognoscitivo donde se ostenta la verdad subjetiva para encontrarse a través de la disposición de ánimo con la verdad objetiva de sí. Es necesario, que aventure por una distinta comprensión de su ser humano que no comprometa su sentido fundamental de existencia. Es, esta falta de comprensión fenomenológica la que hace que el hombre se enfrente a una de serie de crisis existenciales o de sentido en la vida. Y éste es tal vez, de entrada, el papel principal de la orientación filosófica: ofrecer un espacio donde el consultante pueda hacer introspectiva liberándose de toda idea u juicio que tiene de sí, por su acto y en su acto, para hacer posible una "comprensión pura" de sí resignificándose en su ser y vivir, en una especie de intuición fenomenológica. De antemano, adviértase que sólo un detenido examen vivencial de la persona humana permite la apreciación justa del hombre en el cosmos con una esencia suprema de valor único y trascendente. Este es el propósito fundamental del análisis aquí. Entender el papel de la disposición de ánimo, en el consultante, para que éste objetivo fundamental de la orientación filosófica se cumpla.

En consecuencia, vale la pena apresurar en decir, que sólo en la disposición de ánimo (o de espíritu) es que el hombre podrá hacer una 
comprensión fenomenológica de sí. ${ }^{22}$ Anótese, que la filosofía scheleriana parte del presupuesto que: "La disposición de ánimo es la capacidad que el espíritu humano tiene para captar y contemplar contenidos esenciales o aprióricos, a diferencia de los hechos y circunstancias contingentes; más aún, para poder ver en estos sucesos causales leyes necesarias" ${ }^{\text {23 }}$. Esta disposición de ánimo es una especie del "querer puro", del "querer ser", del "saber ser" sobre nuestro valor esencial para hacer posible un transformarse y un crecer. En otras palabras, el entero y más profundo anhelo de querer ser (y de vivir) esencialmente humano. Razón, por el cual, el hombre en la profundidad de su espíritu nace a la iniciativa de entenderse en su acción y por su acción, como el modo único y específico de su más alta esencialidad humana.

En perspectiva de Scheler, como se ha visto, la persona es siempre algo actuante, un acto no sometido a la determinación causal, ni por parte de la masa hereditaria, ni del carácter, ni del mundo circundante; porque aprende en libertad el mundo de las esencias configurando así su valor supremo, justamente como persona. Toda vez, que es capaz del sentimiento del valor y del saber esencial. Pues, en eso consiste su "espíritu", ${ }^{24}$ que lo distingue del animal. Aunque, también el animal posee el intelecto, entendido como cálculo reflexivo, orientado hacia un objeto, y como astucia. El animal no tiene interés alguno ni por la verdad ni por los valores. Sólo por el espíritu, que intuye esencias y valores, se levanta el hombre sobre el apremio y apetencias del momento y considera el en sí del ser y del deber ser. Quien, por tanto, niega al hombre la inteligencia del a priori (conocimiento de esencia), le convierte, sin saberlo, en bruto.

La naturaleza de espíritu en el hombre es lo que lo convierte en sujeto realizador de actos esenciales en el que se experimenta enteramente e íntegramente a sí misma. La persona es así concebida como el ser concreto, sin el cual no se aprehende ninguno de sus actos. En cada acto vive y actúa toda la persona; pero ésta no se agota en sus actos singulares, ni tampoco en el conjunto de ellos. Ya que, nunca puede captarse plena y adecuadamente un acto concreto sin la intención

\footnotetext{
${ }^{22}$ Ibíd. pp. 193-194, 741.

${ }^{23}$ SÁNCHEZ-Migallón, Sergio, La persona humana y su formación en Max Scheler, Pamplona, Ediciones Universidad de Navarra S. A. (EUNSA), 2006. p. 90.

${ }^{24}$ Cfr. SCHELER Max, Hombre y cultura, México, SEP, 1947. pp. 45-47
} 
precedente de la esencia espiritual de la persona misma. No obstante, es sólo a través de los actos en que el hombre se va confinando cada vez más sobre sí mismo e intimidando consigo mismo por grados más altos y dimensiones siempre nuevas, hasta comprenderse $\mathrm{y}$ poseerse íntegramente como actualidad pura. En consecuencia, el centro del espíritu, la persona, no es ni ser sustancial ni ser objetivo, sino tan sólo un "orden estructurado de actos" 25 determinado esencialmente, y que se realiza continuamente a sí mismo en sí mismo. Pues, el modo único y exclusivo de darse es su misma realización de actos, realización de actos en la que, viviendo, se vive al mismo tiempo a sí misma.

Pero, ¿cómo puede ser mirada la esencia? En realidad por "la simple presencia en la conciencia", ${ }^{26}$ es decir, conciencia de algo, del quid al que se dirige la mirada y que le es dado en sí mismo, que se lo representa, lo intuye, lo aprende antes de todo pensar predicativo. Luego la persona sólo comprende, a través de sus actos, la esencia de su ser, la evidencia de su ser. Deja de ser una realidad abstracta e impersonal para ser una realidad concreta y personal. Su mundo de conocer, contemplar, valorar, crece. Se abre a toda conexión esencial por cuanto significa su contorno. Es decir, lo abarca todo. Es la categoría que entreteje un complejo ideal de significaciones constituyéndose en la unidad de significación. Es decir, la persona como unidad de significación es la esencia ideal de significaciones.

La esencia constituida por la significación es inherente a la conciencia de todo cogito actual, ser conciencia de algo. También que la conciencia mira al ser del hombre en sí mismo como una realidad objetiva que esta ahí de la cual es y permanece. Como algo que se enfrenta o está de frente a la misma conciencia. Se trata de darse cuenta de la propia estructura oculta, del sentido de la vida consciente. Sin embargo, esto sólo sucede por un acto de libertad por el que se suspende todo juicio de existencia con relación al mundo. No se trata de duda, sino de hacer presencia en sí mismo.

Desde la perspectiva de las esencias es la persona, manifestación real del hombre, el ser en sí del individuo concreto, no separado de su ser,

\footnotetext{
${ }^{25}$ Ibíd, p.52

${ }^{26}$ SCHELER Max, Ética, op. cit. p. 523. Se entiende aquí como "conciencia" a todo lo que se manifiesta en la percepción interna. O bien, a lo que el sujeto llega por su capacidad de introspección o percepción interior, la comprensión de su esencialidad.
} 
sino él mismo como tal. No se trata de especulación sino del asentamiento del ser. Es la fenomenología del espíritu en el ser humano. La lectura descriptiva y originaria del ser hombre ante toda construcción sistemática o valoración interpretativa. La persona es la causa primera de todo el ordenamiento del ser humano. "Es su independencia, libertad y autonomía existencial con la que es un ser abierto al mundo". ${ }^{27}$ Esto es, en cuanto, se posee a sí mismo, es dueño de sí mismo, es conciencia de sí, es espíritu. La propiedad fundamental de su valor, esencia por sí misma. La radical intimidad y trascendencia del ser espiritual. El modo necesario y evidente de estar dado siempre en la unidad de sus actos intencionales. "El modo hondo de vivir en sí". ${ }^{28}$ La auténtica compenetración de la íntima vivencia en el ser propio. Es el momento del estar dado en sí mismo y por sí mismo con experiencia fenomenológica.

\section{Conclusión: La fuerza de la orientación filosófica que promueve el amor comprensivo de la esencialidad humana.}

En suma: en cualquier nivel cultural es necesario asumir al hombre por sí mismo con profundidad metafísica, como un todo completo en la plenitud de su ser. Para ello, hay que evitar parcialidades: el hombre no sólo es materia, sino espíritu encarnado. De lo contrario el valor de la existencia y esencia humana quedarán comprometidos. Basta ver, por ejemplo, cómo los avances tecnológicos y científicos pulverizan al hombre y muy pocas de las veces lo promueven con un sentido pleno. Los valores de la tecnología y de la ciencia están sobre los valores del hombre. Uno de los aspectos del actual espíritu tecnicista y mecanicista se puede apreciar en la propensión a considerar los problemas y los fenómenos que tiene que ver con la vida interior sólo desde un punto de vista psicológico, e incluso meramente neurológico. De esta manera, la interioridad del hombre se vacía y el ser consciente de la consistencia ontológica del alma humana se pierde progresivamente.

Sin duda, los avances tecnológicos y científicos han mejorado las condiciones de vida pero al mismo tiempo han contribuido a crear una

\footnotetext{
${ }^{27}$ SCHELER Max, El puesto del hombre en el cosmos, op. cit. p. 55

${ }^{28}$ SCHELER Max, Ética, op. cit. p. 555
} 
mentalidad materialista, porque cambiando el modo de vivir han cambiado el modo de pensar. El problema del desarrollo está estrechamente relacionado con el concepto que se tenga del alma o esencia del hombre, ya que el "yo" se ve reducido muchas veces a la psique, y la salud del alma se confunde con el bienestar emotivo faltándole el logos, el sentido que lo integra. Estas reducciones tienen su origen en una profunda incomprensión de lo que es la vida espiritual y llevan a ignorar que el desarrollo del hombre depende también de las soluciones que se dan a los problemas de carácter espiritual. Situación que en muchas de las veces, conduce al hombre a preocuparse más por su vida material-orgánica perdiendo con ello su equilibrio humano con el aumento de contaminación, el uso de sustancias tóxicas, el deterioro progresivo del medio ambiente, la desertización, el daño de la flora y la fauna, los accidentes y las enfermedades, etc. Es claro que pierde todo sentido y valor si no hay una claridad de su esencia y su proyecto.

El progreso y desarrollo humano no puede medirse hoy en día en términos puramente cuantitativos y lineales. El desarrollo debe abarcar, además de un progreso material, uno espiritual, porque el hombre es uno en cuerpo y alma, nacido del amor comprensivo que sólo se alcanza en la experiencia fenomenológica: de ser una unidad convivida del vivir. El ser humano, en consecuencia, se desarrolla cuando crece espiritualmente en esa especie de amor comprensivo o de disposición de ánimo. Lejos de esto, el hombre está inquieto y se hace frágil. La alienación social y psicológica, y las numerosas neurosis que caracterizan las sociedades opulentas, remiten también a este tipo de causas espirituales. Una sociedad del bienestar, materialmente desarrollada, pero que oprime el alma, no está en sí misma bien orientada hacia un auténtico desarrollo. Las nuevas formas de esclavitud, como la droga, y la desesperación en las que caen tantas personas, tienen una explicación no sólo sociológica o psicológica, sino esencialmente espiritual. El vacío en el que el alma se siente abandonada, contando incluso con numerosas terapias para el cuerpo y para la psique, hace sufrir. No hay un desarrollo pleno ni un bien común universal sin el bien espiritual y moral de las personas, consideradas en su totalidad de alma y cuerpo. Se necesita lograr un crecimiento sostenible y compatible con la naturaleza humana ${ }^{29}{ }_{-}$su ser

${ }^{29}$ La naturaleza humana apunta a lo que es rasgo específico común a todos los seres humanos. Se HASER. Revista Internacional de Filosofía Aplicada, nº 1, pp. 67-89 
material y su ser espiritual-, su esencia y valor. La investigación y la innovación no tienen un único camino marcado de antemano, sino que más bien son elecciones de valores, decisiones humanas al fin y al cabo, las que determinan los resultados y productos conseguidos.

La disposición de ánimo (de espíritu) ${ }^{30}$, en un sentido profundo y serio, es fundamental para que el hombre se abra hacia la fenomenología del valor. Proclame en un sentido puro y práctico desde situaciones vivenciales concretas la forma especial de ser y existir del hombre: el ser que integra en sí una esencia, unos accidentes y una existencia. Existencia concreta constituida como tal por la actualidad o el acto de existir con la pluralidad de dimensiones que comporta: intelectivas, volitivas, afectivas, relacionales, etc. Existencia en la que el hombre sólo puede vivir actuando para ser más. El sentido se resalta con la máxima socrática "conócete a ti mismo" 31 , porque es la primera conciencia de que el hombre puede ser más hombre; con la capacidad de disfrute por la verdad, la justicia, la belleza, el bien y la vocación a la trascendencia. Conocerse a sí mismo significa preguntarse por el bien de uno mismo y el modo de alcanzarlo para lograr la realización del ser hombre.

Se trata de un humanismo que construye una vida cuya universalidad es el amor. El amor como la fuente y motor del crecimiento de la persona. El amor como la médula de la esencia humana. El logos que lo eleva a una riqueza de valor superior y a un desarrollo integral en virtud de su ser y obrar. "Antes de ens cogitans o de ens volens es el hombre un ens amans" 32 . El acto fundamental del ser humano que lo convierte en un ser de comprensión espiritual en el ser. Es decir, que lo convierte en un ser de comprensión espiritual en el valor por sí mismo y en sí mismo. El amor donde el afán de ser más hombre en el concurso con lo otro, en el concurso del ser propio con el ser se amplía. Se trata, entonces, del amor comprensivo espiritual en el ser como la forma auténtica de ser hombre. Es conciencia de ser y de poder ser. En

refiere a lo que es específico del hombre en cuanto tal, es decir, señala lo que es esencialmente humano, lo que hace que el hombre no sea nada ni nadie más que hombre: La manifestación de un ser espiritual, un espíritu encarnado.

${ }^{30}$ Entiéndase, la disposición de ánimo: como el deseo de querer una vida valiosa, de resignificar la vida en la comprensión espiritual del ser esencial del hombre.

${ }^{31}$ Cfr. REALE Giovanni y ANTISERI Dario, Historia del pensamiento filosófico y científico: Antigüedad y Edad Media, Tomo I, Barcelona, Herder, 1995. p. 88

${ }^{32}$ Cfr. SCHELER, Max, Ordo amoris, Madrid, Caparrós Editores, 1996. p. 27 
definitiva, indudablemente el hombre es, por encima de todo, sujeto de su ser y de obrar en la compresión de este amor espiritual, es decir, el vivir y experimentar siempre con esencialidad, en cada acto que se realiza, la propia naturaleza.

Tres elementos pueden distinguirse aquí. Primero, el amor es un "movimiento"; esto es, un acto espontáneo, no un estado pasivo o disfrute meramente subjetivo. Segundo, se dirige a un sujeto individual valioso; lo cual excluye el amor a idealidades abstractas (incluidos los valores mismos o la humanidad en general). Tercero, la dinámica del amor se dirige a valores más altos, que no supongan violentar la naturaleza del sujeto personal amado, sino que le pertenezcan de una manera peculiar, según su esencia ideal. Efectivamente, ese amor personal descubrirá, en uno mismo y en otros, la idea de persona que todo ser humano tiene ante sí, sea más o menos consciente de ello, que responde a sus íntimas aspiraciones y que se dibuja como ideal normativo. Asimismo, lo más determinante de la persona — sea la que de hecho vive, sea la que idealmente invita a ser vivida - es precisamente su amor, su modo de amar. Modo cuya esencia viene definida por dos coordenadas: la anchura del espectro axiológico de lo amado, y las relaciones según de preferibilidad, o bien, de disposición de ánimo que entraña. A ese modo de amar Scheler lo llamará, con la expresión agustiniana, ordo amoris: "Quien posee el ordo amoris de un hombre posee al hombre. Posee respecto de este hombre, como sujeto moral, algo como la fórmula cristalina para el cristal" ${ }^{3}$. La función del amor es determinativa y consiste en su capacidad de desconectar al hombre del interés impulsivo, y le apega, a la esfera de lo vital para interesarlo espiritualmente en la esfera de lo esencial. Cuanto más puro es el vivir, más axiológicamente alto es el sentido de la vida, lo esencial de la vida. El cumplimiento de su misma esencia.

En síntesis, la orientación filosófica su fuerza se establecerá, en que, a través de la disposición ánimo o de espíritu el consultante hará una compenetración, o comprensión espiritual, o amor espiritual de sus vivencias. Pero, esa compenetración o comprensión espiritual no sólo se ha de reducir a la categoría del saber o conocer, sino del ser, y precisamente en la forma de una totalidad (unidad convivida del vivir) de

\footnotetext{
${ }^{33}$ Ibidem.
} 
tiempo, actos y procesos; o del proceso por el que el espíritu (la persona) crece transformándose él mismo con carácter esencial u ontológico. La orientación filosófica se convierte así, en un espacio oportuno donde la persona busca en un marco reflexivo, pero sobre todo, en la disposición de ánimo su propia pauta y dirección de sentido esencial de vida: De llegar a ser (de hacerse a sí mismo) la persona que auténticamente le corresponde y que nace de su aspiración más profunda de ser de un modo y no de otro. De poseer una determinación individual distinta, de poseer una dirección de desarrollo moral de suyo individual y única. De hacer posible y de asumir por sí mismo la posibilidad de una radical transformación moral de sí. De poseer un modo único y diverso de apertura y riqueza axiológica para su realización humana con voluntad y acción práctica.

\section{Caso práctico: La persona y el conflicto relacional}

Aunque es un hecho que el hombre nace, crece, se desarrolla como sujeto de relaciones entre: el Yo, el Tú y el Ello. ${ }^{34}$ Es muy cotidiano que, de cara a lo complejo de sus relaciones se enfrente a situaciones de crisis, a la falta de amor comprensivo en su apertura y a la capacidad de religación: salir de sí y volver a sí. Experiencia vivida de modo diverso por el ser humano y su unidad de actos manifestantes del convivir, que lo conducen a la búsqueda de una comprensión esencial en sus relaciones y encuentros consigo mismo, los demás y el mundo. Caso, en el cual, la orientación filosófica se presentará como una oportunidad para resignificar y resituar fenomenológicamente las relaciones humanas desde la perspectiva del amor comprensivo. Un espacio en el que los consultantes relean sus modos cotidianos de relaciones humanas, analicen sus significados, sus creencias y valores con respecto a ellos. Encuentren un modo significante y significativo de unidad en la diversidad relacional.

Así por ejemplo, obsérvese aquí, el caso que presenta Lizeth Govea. Ella dice: No saber cómo terminar su relación de noviazgo, de casi ya, tres años. Tiene miedo, además, cómo vaya a reaccionar su novio frente

\footnotetext{
${ }^{34}$ Entiéndase el Yo, como la "Mismidad"; el Tú, como la "Otredad" y el Ello, como la "cosa", es decir, los objetos.
} 
a ésta decisión. Ella es una joven universitaria de 23 años de familia liberal. En cambio, su novio, aunque un joven de su misma edad, es proveniente y formado por una familia conservadora.

Ella, con angustia declara, que desde el principio no sentía nada por él. Pero siendo un chico tierno y amoroso, y aprovechándose de eso, se dejó llevar por la relación sin pensar en los efectos emocionales o afectivos que provocaría. Y es que para ella: "¡A quién le importan los sentimientos! Cada quien se mueve por sus propios intereses. Las relaciones giran entorno a algo funcional o útil" Sin embargo, él ha dado todo de sí. La ha tomado en serio. Ha sido puro en sus sentimientos e inocente. En cambio, ella sólo consideró la relación como una especie de free, que también, por el modo de ser, de él con ella, nunca se atrevió a planteárselo. Por tal motivo, siente que le está haciendo daño, pues ya le reclama posesivamente y cada vez más; cuando no está con él. Y la razón, que ella considera, no es cualquier cosa. Se le ha entregado a él en la intimidad como la mujer de sus sueños. Tal, es así, que se están acostumbrando a estar juntos, pero peleando o discutiendo por cualquier cosa. Más y más, si ella se muestra fría y calculadora. Él, en cambio, se muestra agresivo cuando siente que le va a perder. $Y$ es, a esto, a lo que ella exactamente, le tiene miedo. Miedo a que sufra, a lastimarlo y a su reacción frente a sí mismo o a ella. El miedo a que se pueda hacer daño por no perdonarse el haber sido engañado, o bien, el no aceptar perderle. Y lo ha pensado como tal, que ha dejado pasar el tiempo y no ha tenido la fuerza suficiente para tomar una decisión definitoria. A demás, de darle demasiada importancia al querer ser y vivir de él, que al propio querer ser y vivir, aceptando dominio y resignación; es decir, dejando de querer ser $y$ vivir en sí para pasar a querer ser y vivir en el otro. Ella había preferido la enajenación, el sometimiento de su voluntad a la voluntad del otro en castigo a su deshonestidad, a su falta de sinceridad con él. ¿Por qué lo asumió de ese modo? Se preguntaba ella. Por que sólo así, todo marcha bien, y si se oponía, comenzaban los conflictos, las discusiones, las amenazas. Nacían las sentencias más agresivas y amenazantes para él: ¡Nunca te he querido! ¡Te odio!... A tal grado, que se perdía la cordura y el respeto. No obstante, ello ya le había cansado, estaba perdiendo su propia identidad dejando de ser ella misma y por lo tanto, feliz. Su forma de querer ser y vivir ya le eran ajenos. 
Así, que arrojada frente a la angustia existencial en la que se encontraba Lizeth, y de cara frente a sí misma, con la ayuda del orientador filosófico, evaluó su capacidad de razonar, de articular un pensamiento razonable, de acceder a experiencias de conciencia con el fin de asumir la tarea de clarificar su situación de manera ordenada y clara. Téngase en cuenta, o bien, adviértase, que cuando el asesor/a puede orientar y abrir puertas que inviten a la reflexión, si no es correspondido con un compromiso personal, la tarea se torna más difícil. De que en la práctica filosófica, el aspecto reflexivo a de estar dirigido a ordenar el mundo interno (reconstruir la racionalidad, reconstruir la conciencia, clarificar las sensaciones externas e internas) de las personas y al modo en el que lo hace. Cada situación vivencial del ser humano es posible ser pensada, analizada y demostrada en la filosofía con una diversidad de método. Sin embargo, no por ello hay que dejar de buscar el método que más se adecue o simplifique la complejidad de la realidad vivencial personal del consultante. Por último, son necesarios para el consultor ( $u$ orientador filosófico) la autonomía, la responsabilidad, la serenidad, la seguridad, la pluralidad de técnicas y habilidades ante situaciones de improvisación para que no se pierda la armonía en el juego de la consulta y la calidad de resultados.

En consecuencia, vale la pena hacer notar en el caso de Lizeth, algunas de sus directrices de pensamiento expresadas bajo los siguientes puntos: ¿Debe o no terminarse una relación si no se siente bien consigo mismo? ¿Debe importar más, en una relación querer ser y vivir yo, que el querer ser y vivir del otro? En una relación del Yo-Tú, ¿cuál es la actitud más apropiada racional, volitiva y afectivamente asumir? ¿Debe haber ventajas y desventajas en relación a uno y con respecto a los otros? ¿El querer ser y vivir puro es inconciliable con el querer ser y vivir egoístamente? ¿Qué ciega a la disposición de ánimo o de espíritu revelar el sentido o la intención sobre cualquier relación? ¿Qué puede cegar la propia medida de amar y de ser amado? ¿Es justificable, que en algunas ocasiones, se prefieran callar el sentido o la intención? ¿Qué ventajas y desventajas representa revelar el sentido o la intención en una relación? ¿Hasta dónde se está dispuesto a enfrentar las consecuencias positivas y negativas de los actos, de las tomas decisiones? ¿Por qué satisface más la aceptación, el reconocimiento del otro que el propio rechazo? ¿Por qué se le tiene miedo a la frustración, al fracaso, al sufrimiento de sí mismo o 
del otro? ¿Por qué es una ley de la vida encontrar la propia felicidad queriendo, al mismo tiempo, la felicidad del otro? Ahora bien, desde el punto de vista del orientador filosófico (sobre todo, del scheleriano): ¿qué es lo que se le olvida al ser humano en las crisis de sus relaciones con los otros? Aquella necesidad de reconocimiento y de consentimiento, en el uno y el otro; o bien, de amor comprensivo en la diversidad de vínculo de la que es capaz como sujeto relacional. Porque la decisión de ser, de querer ser y vivir dentro del seno de una relación necesariamente tienen que reconocerse y consentirse por lo fáctico del Yo-Tú y la armonía [de la unidad de pensar y de ser] de las intenciones interpersonales. Una unidad de ser y de pensar que sólo puede sustentarse en lo esencial del ser humano, que es su capacidad de amar, es decir, de buscar la parte que tiene el otro de ser para el cumplimiento del propio ser. Así, por ejemplo, la paternidad y la filiación es una experiencia esencial de amor. Sin embargo, en las relaciones de padres e hijos se discutirán siempre el hecho de la libertad y de la responsabilidad... pero si los planteamientos [o los modos en que se viven las relaciones] no son bien entendidos entre unos (padres) y otros (hijos) se pensará que no hay amor.

Basta ver, que en la misma experiencia que es más amplia que la experiencia noética (conceptual); el origen de las relaciones humanas comienza cuando se enfrentan dos deseos, dos conciencias deseantes de reconocimiento. No obstante, cuando en el deseo de reconocimiento se interpone el deseo de dominio, de posesión, de sometimiento y por ningún motivo, algo unificado: la fractura es evidente. El conflicto es evidente porque el trato con el tú, es como un "él" anónimo, como si fuera una cosa que, termina manipulándole como un "ello". Se le niega al "tú" su ser único e irrepetible. Principalmente, cuando la posesión, el dominio y el sometimiento, han sido estimados como el modo natural y cotidiano del hombre de ser reconocido. Y se olvida, que tal reconocimiento, es un consentimiento mutuo y continuado del querer ser y vivir en cada acto relacional.

Tanto, el Yo y el Tú buscan el reconocimiento, que no puede darse en una lucha de dominio, porque es el principio del enfrentamiento, es decir, de dos conciencias enfrentadas, pues una conciencia niega a la otra e intenta el sometimiento a la fuerza hasta que lo logra. Hecho que carece de sentido porque, cuando una de las dos conciencias se somete pierde 
voluntad y autonomía propia. Esto se ha confirmado ya, como se ha visto, en el caso de Lizeth. Cae en la totalidad de la insatisfacción negándose a sí misma. Pues al ceder al dominio, ya no se siente una persona autónoma y libre. Queda paralizada totalmente, en aquello que la humaniza, convirtiéndose en esclava frente a la figura que la domina, al haber cedido su derecho de ser reconocida. Porque ¿quién ama, sin la necesidad de ser amado? ¿Quién respeta, sin la necesidad de ser respetado? ¿Quién escucha, sin la necesidad de ser escuchado? ¿Quién permite que se expresen, sin que se lo permitan a sí mismo?

Hablando abiertamente en el caso de la relación de amor, que se establece entre dos conciencias libres, cuando el nivel de amor entre uno y otro son distintos, es decir, que uno ame más y otro ame menos, la posesión, el dominio y el sometimiento permanecen. La conciencia que ama más, arrojada fuera de sí, es la que más se somete de lo que hay de ella de sensible, de emocional. En cambio, la conciencia que ama menos, arrojada fuera de sí, es la que más domina, la que más manipula. En este caso, se revela la falta de un amor comprensivo, de la conciencia que busca dominar y la conciencia que termina siendo sometida.

Asumiendo que cada conciencia deseante es sólo la mitad de sí mismo, el amor comprensivo permitirá a las conciencias salir de sí en búsqueda de aquella parte que le complementará en su ser mismo. Porque el amor comprensivo es un anhelo de aquello que tiene el otro de ser para el cumplimiento del propio ser. Anticípese que sólo en el amor comprensivo se alcanza una conciencia plena de la necesidad de reconocimiento mutuo, que ha de sobreponerse a la sed de dominio y de sometimiento. De lo contrario, ¿de qué otro modo el hombre puede crecer en la estatura de su humanidad?

De entrada, no en las relaciones donde las conciencias deseantes sólo buscan cubrir sus necesidades materiales convirtiendo al otro en alguien funcional, útil. No en donde a la relación, se sobrepone el compromiso o el contrato. Aunque vale reconocer que el amor es intencional, en cuanto lo que el Tú busca y espera en el otro, conduce regularmente a confusiones erróneas; y a entender por amor aquello que no es. De tal manera, que la clarificación será fundamental en los consultantes que son capaces de abrirse por sí mismos, a perspectivas nuevas y significativas con el apoyo del orientador filosófico. Aquél que tiene como habilidad conducir a las personas a un pensamiento crítico- 
reflexivo desde la lógica del corazón, que aspira a conocer y amar lo esencial. Por lo tanto, la orientación será, un espacio para lo formativo de las conciencias deseantes en búsqueda de reconocimiento.

\section{Bibliografía}

DE LA CRUZ VALLES, Antonio, "El concepto de Espíritu en la Antropología de Max Scheler: Un estudio sobre El puesto del Hombre en el Cosmos". A Parte Rei: Revista de Filosofía, núm. 31. Enero de 2004. GUERRA López, Rodrigo, Volver a la persona, el método fenomenológico de Karol Wojtila, Caparrós Editores, México, 2002.

KANT, Manuel, Crítica de la razón práctica, Porrúa, México, 2005(13ª). SÁNCHEZ-Migallón, Sergio, La persona humana y su formación en Max Scheler, Ediciones Universidad de Navarra S. A. (EUNSA), Pamplona, 2006.

SANTAMARÍA, M.G., Acción, Persona, Libertad: Max Scheler-Tomás de Aquino, Ediciones de Universidad de Navarra (EUNSA), España, 2002.

SCHELER, Max, Ética, Nuevo ensayo de fundamentación de un personalismo ético, Caparrós Editores, Colección Esprit, Madrid, 2001.

- El puesto del hombre en el cosmos. Losada, Buenos Aires, 1899.

- El resentimiento en la moral, Caparrós Editores, Madrid, 1998. Traducción del original alemán por José Gaos: Das Ressentiment im Aufbau der Moralen.

- Esencia y Formas de la simpatía, Sígueme, Salamanca, 2005. Tradujo José Gaos sobre el original alemán Wesen und formen der sympathie (1923).

- Gramática de los sentimientos, Lo emocional como fundamento de la ética, Crítica, Barcelona, 2003. Título original: Grammatik der Gefühle. Das Emotionale als Grundlage der Ethik (Traducción castellana de Daniel Gamper).

- Hombre y cultura. SEP, México, D. F. 1947.

- La idea del hombre y la historia. Siglo Veintiuno, Buenos Aires, 1967. 
- Los ídolos del autoconocimiento, Sígueme, Salamanca, 2003. Tradujo Ingrid Vendrell Ferram sobre el original alemán: Die Idole der Selbsterkenntnis.

— Ordo Amoris, Caparrós Editores, Madrid, 1996.

- Muerte y supervivencia, Encuentro Ediciones, S.A. Madrid. 2001.

VERGÉS RAMIREZ Salvador, "La persona es un <valor por sí misma> según Max Scheler", Pensamiento, vol. 55, núm 212, mayo-agosto 1999. págs. 245-267.

WOJTYLA, Karol, Max Scheler y la Ética Cristiana, BAC, Madrid, 1986.

WOJTYLA, Karol, Persona y Acción, BAC, Madrid, 1982.

WOJTYLA, Karol, Educación en el amor, BAC, Madrid, 1990.

\section{Anexo: glosario del autor}

1. Amor. Es el movimiento en que todo sujeto concretamente individual que porta valores, llega a los valores más altos posibles para él con arreglo a su determinación ideal.

2. Antropología Filosófica. Ciencia fundamental de la esencia y de la estructura esencial del hombre; de su relación con los reinos de la Naturaleza (inorgánico, vegetal, animal) y con el fundamento de todas las cosas; de su origen metafísico y de su comienzo físico, psíquico y espiritual en el mundo, de las fuerzas y poderes que mueven al hombre y que el hombre mueve; de las direcciones y leyes fundamentales de su evolución biológica, psíquica; histórico-espiritual y social, y tanto de sus posibilidades esenciales como de sus realidades.

3. Conciencia. Propiedad del espíritu humano de reconocerse en sus atributos esenciales y en todas las modificaciones que en sí mismo experimenta. La forma superior, propia tan sólo del hombre, del reflejo de la realidad objetiva.

4. Conocimiento. Es la apertura del espíritu a las determinaciones de lo dado y captado por una especie de intuición fenomenológica. 
5. Conocimiento apriórico. Significa que la intuición de las esencias es independiente de toda esfera de lo que puede ser observado, descrito y aprobado por experiencia y de todo aquello que pueda entrar en una eventual explicación causal.

6. Disposición de ánimo (o de espíritu). Es la capacidad que el espíritu humano tiene para captar y contemplar contenidos esenciales, es decir, un "querer puro", un "querer ser", un "saber ser" sobre nuestro valor esencial para hacer posible un transformarse y un crecer. En otras palabras, el entero y más profundo anhelo de querer ser (y de vivir) esencialmente humano. Cuanto más puro es el vivir, más axiológicamente alto es el sentido de la vida, lo esencial de la vida. El cumplimiento de su misma esencia.

7. Esencia. Aquello que constituye la naturaleza de las cosas, lo permanente e invariable de ellas.

8. Espíritu. Se llama así a todo lo que posee la esencia del acto, de la intencionalidad y de la implicación de sentido. En otras palabras, hablar de espíritu es hablar de la persona, de todo sujeto personal.

9. Experiencia. Es la vivencia del sujeto espiritual frente a lo dado en sí y por sí mismo.

10. Fenómeno. Lo que aparece o se manifiesta en sí mismo, o sea, como es, en sí, en su esencia. Como el puro y simple aparecer del ser en sí.

\section{Filosofía. Amor hacia lo esencial.}

12. Persona. Es el acto de vivir como valor supremo y centro de todos los valores, de las acciones y de las cosas que le están subordinadas y en cuya realización según la ley de preferencia axiológica, constituye su perfección moral. La persona es la unidad inmediatamente convivida del vivir, más no una cosa simplemente pensada fuera y tras lo inmediatamente vivido. La persona no es un sustrato anterior a la acción. La persona es, en cierto sentido, su acción espiritual. 
13. Por sí, o para sí. Lo que es en virtud de su propia esencia y no por otra cosa.

14. Reducción fenomenológica. Consiste en que, de parte del objeto, cualquiera que sea éste (sea físico, psíquico, matemático, vital o relativo a las ciencias morales), se hace abstracción de su existencia contingente, y se considera su quid puro, es decir, su esencia. De esta manera, aparece un amor desinteresado que aprecia y capta la esencia y el valor de las cosas en sí mismas sin restricción. Así se logra la intuición de esencias.

15. Sujeto o "portador del espíritu". Aquel ser cuyo trato con la realidad exterior se ha invertido en sentido dinámicamente opuesto al animal.

16. Valor por sí mismo. Cualidad esencial y fundamental de los entes (personas, acciones, cosas): el ser. 
